\title{
1 Dead infant carrying by chimpanzee mothers in the Budongo Forest
}

3 Adrian Soldati ${ }^{1,2,3}$, Pawel Fedurek ${ }^{3,4,5}$, Catherine Crockford ${ }^{4}$, Sam Adue $^{3}$, John Walter

4 Akankwasa $^{3}$, Caroline Asiimwe $^{3}$, Jackson Asua $^{3}$, Gideon Atayo ${ }^{3}$, Boscou Chandia $^{3}$, Elodie

5 Freymann $^{3,6}$, Caroline Fryns ${ }^{2,3}$, Geresomu Muhumuza $^{3}$, Derry Taylor ${ }^{1,3}$, Klaus

6 Zuberbühler ${ }^{1,2,3}$, Catherine Hobaiter ${ }^{1,3}$

8 Affiliations:

$9{ }^{1}$ School of Psychology and Neuroscience, University of St Andrews, St Andrews, UK

$10 \quad{ }^{2}$ Department of Comparative Cognition, Institute of Biology, University of Neucha $\square$ tel,

$11 \quad$ Neucha $\square$ tel, Switzerland

$12{ }^{3}$ Budongo Conservation Field Station, Masindi, Uganda

$13{ }^{4}$ Department of Primatology, Max Planck Institute for Evolutionary Anthropology, Leipzig,

14 Germany

$15{ }^{5}$ Division of Psychology, Faculty of Natural Sciences, University of Stirling, Stirling, UK

$16{ }^{6}$ Department of Anthropology and Museum Ethnography, University of Oxford, Oxford, UK

18 Email of corresponding author: as391@st-andrews.ac.uk

20 ABSTRACT

21 It has been suggested that non-human primates (hereafter primates) can respond to deceased

22 conspecifics in ways that suggest they experience psychological states not unlike humans,

23 which would indicate they exhibit some notion of death. Here, we report long-term

24 demographic data from two East African chimpanzee groups. During a combined 40-year

25 observation period we recorded 191 births of which around a third died in infancy, mostly 
26 within the first year. We documented the post-mortem behaviour of the mothers and found

27 that Budongo chimpanzee mothers routinely carried deceased infants after their death,

28 usually until the body started to decompose after a few days. However, we also observed

29 three cases of extended carrying lasting for more than 2-weeks, one of which was followed

30 by the unusual extended carrying of a substitute object and another which lasted three

31 months. In each case, the corpses mummified. We discuss these data in view of functional

32 hypotheses of dead infant carrying in primates and the potential proximate mechanisms

33 involved in this behaviour, including psychological processes managing infant loss in

34 humans such as grieving.

\section{INTRODUCTION}

37 Primate thanatology, the study of the behaviour and underlying physiological and

38 psychological factors associated with dead or dying individuals in non-human primates

39 (hereafter primates), continues to raise important questions about human uniqueness

40 (Anderson 2016, 2018; Anderson et al. 2018). Humans experiencing the loss of socially close

41 individuals experience significant psychological trauma with long-term physiological effects,

42 including symptoms of post-traumatic stress disorder, anxiety and depression, and increased

43 used of health-care resources (Figley et al. 1997; Parkes et al. 1997; Lannen et al. 2008).

44 Given our biological and social similarities, other primate species - in particular other great

45 apes - may experience similar cognitive and physiological changes. Cross-species

46 comparisons, especially in primates, are often used to reveal past evolutionary trajectories of

47 the hominid lineage. Primate behaviour and physiology in relation to deceased individuals

48 provide valuable data to better understand the origins of why humans are so powerfully

49 affected by death. More generally, primate responses to death may provide further insight 
50 into other aspects of animal cognition, such as animacy or the perception of time (Gonçalves

51 and Carvalho 2019).

53 Because death is unpredictable and rarely observed in wild primate communities, the

54 available datasets are usually anecdotal and descriptions of events are often incomplete

55 (Watson and Matsuzawa 2018; Ramsay and Teichroeb 2019). Nevertheless, an increasing

56 number of primate groups have been habituated to human observers (Kappeler et al. 2012),

57 which has led to more frequent reporting and more systematic efforts to extract patterns of

58 behaviour in responses to death (Anderson 2020). These observations have led to claims that

59 primates respond to death in ways that are similar to humans, by producing strong emotional,

60 social, and exploratory responses (Watson and Matsuzawa 2018; Gonçalves and Carvalho

61 2019). Among non-human animals, the emphasis on primates may result from easier

62 detection, given the relatively large number of long-term studies, and observations from

63 corvid, elephant, and cetacean species suggest that some understanding of death may be

64 widespread among a wide range of long-lived highly-social species (Reggente et al. 2016;

65 Gonçalves and Biro 2018; Bercovitch 2020).

67 Here, we focus on a particularly remarkable behaviour seen in many primates, dead infant

68 carrying by mothers, which in chimpanzees typically occurs for a period of up to three days

69 (Gonçalves and Carvalho 2019). Dead infant carrying (also referred as infant corpse carrying)

70 is the most frequently reported thanatological behaviour and shows substantial variation in

71 accompanying behaviours across primate species (Fernández-Fueyo et al. 2021), as a result, it

72 offers rich data against which to explore possible explanatory factors. This behaviour has not

73 only been reported in chimpanzees (Matsuzawa 1997; Hosaka et al. 2000; Kooriyama 2009;

74 Biro et al. 2010) but also in bonobos (Fowler and Hohmann 2010; Tokuyama et al. 2017), 
75 gorillas (Warren and Williamson 2004; Masi 2020), chacma baboons (Carter et al. 2020), red

76 colobus (Georgiev et al. 2019), geladas (Fashing et al. 2011), bonnet and lion-tailed

77 macaques (Das et al. 2019), Japanese macaques (Sugiyama et al. 2009; Takeshita et al. 2020),

78 and vervet monkeys (Botting and van de Waal 2020), while failed apparent attempts at

79 carrying have been observed in ring-tailed lemurs (Nakamichi et al. 1996) and marmosets

80 (Thompson et al. 2020). Several hypotheses have been put forward to explain the function of

81 and motivation for this behaviour (Table 2; for a review see: Watson and Matsuzawa 2018;

82 Gonçalves and Carvalho 2019).

84 Within an increasingly large field of hypotheses - some of which are mutually non-exclusive

85 - there are some natural groupings based on similarity in the suggested mechanisms or

86 explanations. A first group of hypotheses presumes that primate mothers are unable to

87 understand the ramifications of death and their behavioural responses are simply side effects

88 of evolved physiological mechanisms. Specifically, the 'unawareness hypothesis' states that

89 mothers are unable to discriminate between temporarily unresponsive and irreversibly

90 deceased individuals and simply try to avoid the costs of premature abandonment (Hrdy

91 1999). The hypothesis predicts that mothers are unable to understand their infants' state and

92 continue providing maternal care (e.g. grooming) and try to elicit responsiveness (e.g.

93 poking, smelling). With increasing time, the ambiguity will dissolve due to the accelerating

94 decomposition of the corpse, which is usually mediated by local climate. A second prediction

95 therefore is that dry and particularly hot or cold conditions favouring mummification should

96 favour prolonged carrying of dead infants (see also 'climate hypothesis': Matsuzawa 1997;

97 Fashing et al. 2011). The 'post-parturient condition' hypothesis (also referred as 'hormonal',

98 see Gonçalves and Carvalho 2019) similarly proposes that the maternal physiological

99 conditions associated with pregnancy and birth favour persistent care of the dead infant as 
100 long as the mother is lactating or until resumption of ovulation (Biro et al. 2010), for example

101 indicated by sexual swelling (Kaplan 1973). After giving birth, the endocrine system of the

102 mother releases hormones (e.g. oxytocin) that stimulate maternal behaviours (Keverne 1988;

103 Bercovitch 2020). Here, the younger the infant at time of death the longer the carrying

104 period.

106 A second kind of hypotheses assumes that primate mothers can have a notion of death,

107 provided they have relevant personal experience. Specifically, the 'learning about death'

108 hypothesis states that chimpanzees do not intuitively understand death but can acquire the

109 notion by learning to attend to the relevant cues (Cronin et al. 2011). Here, the predication is

110 that experienced mothers will be aware of the irreversible change and, unlike first-time

111 mothers, should have shorter dead-infant carrying periods. An alternative hypothesis, the

112 'grief-management hypothesis', also assumes that chimpanzees possess a notion of death, and

113 suggests dead-infant carrying represents a consoling strategy to cope with grief. This

114 hypothesis predicts that mothers who are able to carry their dead infants experience lower

115 levels of 'stress' hormones (i.e. glucocorticoids) than mothers who could not or did not carry

116 them (Nicolson 1991). A recent study by Girard-Buttoz and colleagues (Girard-Buttoz et al.

117 2021) reported elevated cortisol levels in infant chimpanzees who lost their mothers,

118 supporting the notion that disruption of the mother-infant bond leads to elevated stress.

119 Similarly, female baboons experience high levels of glucocorticoids when losing an ally to

120 predation and in periods of infanticidal attacks (Engh et al. 2006a, b). Dead infant carrying,

121 therefore, could be a strategy to cope with stress associated with infant loss.

123 A third group of hypotheses are agnostic about whether chimpanzees possess a notion of

124 death but proposes various adaptive mechanisms that favour post-mortem mothering 
125 behaviour. First, the 'learning-to-mother hypothesis' states that dead-infant carrying

126 improves maternal skills (Warren and Williamson 2004), predicting that the behaviour should

127 mainly be observed in inexperienced primiparous females. Second, the 'maternal-bond

128 strength hypothesis' predicts that mothers with older infants share a stronger bond and are

129 thus more likely to show extensive carrying as compared to mothers with younger infants

130 (Watson and Matsuzawa 2018).

132 The existence of multiple - sometime contrasting - hypotheses is likely a reflection of the

133 small and highly variable data available and the diversity of potential drivers of this

134 behaviour across different species. A recent systematic study on primates ( $\mathrm{n}=18$ species)

135 showed that duration of infant carrying is affected by the age of the mother, with older

136 mothers carrying for longer periods (Das et al. 2019), in contrast with previous findings by

137 Sugiyama and colleagues who found no effect of age (Sugiyama et al., 2009). Infants that

138 died of sickness were carried for longer than those who were stillborn or victims of

139 infanticide, while the age of the infant did not influence duration of carrying (Das et al.

140 2019). Although dead infant carrying is a shared but rare behaviour in primates, carrying

141 duration seems to be the longest in great apes (Fernández-Fueyo et al. 2021), particularly in

142 chimpanzees (Das et al. 2019). Wild chimpanzees have higher levels of infant mortality

143 compared to captive conspecifics (Courtenay and Santow 1989; Hill et al. 2001), which

144 provides increased opportunities to observe mothers' responses to their infants' death

145 (Watson and Matsuzawa 2018). Chimpanzee mothers typically carry their dead infants for a

146 few days, though a recent analysis of the largest chimpanzee dataset ( $n=33$ cases) did not

147 provide clear support for any of the previous hypotheses (Lonsdorf et al. 2020). Despite this,

148 it was proposed that the 'unawareness hypothesis' is unlikely because of the presence of

149 atypical carrying postures and sensory cues after death compared to those displayed towards 
150 alive infants (Lonsdorf et al. 2020). More recently, a study using the largest primate database

151 to date ( $n=409$ cases and $n=50$ species) found that dead infant carrying was more likely to

152 occur when the cause of death was non-traumatic and when mothers were younger

153 (Fernández-Fueyo et al. 2021). Here, we revisit the discussion on the potential reasons behind

154 dead infant carrying by female chimpanzees with a 40-year dataset of two study groups of the

155 Budongo Forest, Uganda, including three detailed observations of extended dead infant

156 carrying by two different females.

METHODS

\section{Study site and subjects}

160 The Budongo Forest Reserve is a semi-deciduous tropical rain forest located along the

161 Western Rift Valley in Uganda. This reserve is made of $793 \mathrm{~km}^{2}$ of protected forest and 162 grassland, including $482 \mathrm{~km}^{2}$ of continuous forest cover (Eggeling 1947). The reserve

163 contains a population of approximated 600 East African chimpanzees (Pan troglodytes

164 schweinfurthii). Our observations took place in two adjacent communities, Sonso and

165 Waibira, studied regularly by researchers and followed on a daily basis by field assistants

166 since 1990 and 2011 respectively (Reynolds 2005; Samuni et al. 2014).

168 At the time of the events, the Waibira community contained an estimated 120 individuals, 96

169 of which could be individually recognised. Individuals involved in the first event were Ketie

170 (KET), a 20-year old adult primiparous female (estimated birth 1998) and her 2-year old

171 female infant Karyo (KYO) born in December 2015. The Sonso community contained 65

172 named individuals, in addition to three unnamed females in the process of immigrating. The

173 individuals involved in the event were Upesi (UP), a 21-year old parous female (estimated

174 birth 1999) and a) in the second event, her recently born unnamed unsexed infant UP3, born 
175 mid-September 2020 and b) in the third event, her $4^{\text {th }}$ born unnamed unsexed infant UP4,

176 estimated birth $7^{\text {th }}$ August 2021. Her first two infants (born in 2017 and 2018) were victims

177 of within-community infanticide before reaching a month old (see Leroux et al. 2021 for one

178 reported case).

180 In this paragraph we consider the scope for bias in our study subjects by using the

181 STRANGE framework to report potential sampling biases in our study (Webster and Rutz

182 2020; Rutz and Webster 2021). The Sonso community are of typical size whereas the

183 Waibira community are particularly large as compared to that of other chimpanzees (in a

184 recent comparison of 18 groups across three subspecies: P.t. schweinfurthii, P.t. troglodytes,

185 P.t. verus; communities range from 7-144 individuals with a mean 42; within these data the

186 East African sub-species (P.t. schweinfurthii) range is 18-144 with a median 49; Wilson et al.

187 2014). Sonso have a typical female-basied sex ratio among mature individuals (M:F; 1:1.7),

188 whereas the Waibira community have more unusual evenly-balanced sex ratio among mature

189 individuals (M:F; 1:1.2; mean among 9 P.t. schweinfurthii communities 1:1.7; Wilson et al.

190 2014). Of relevance to sampling biases in infant mortality and opportunities to carry dead

191 infants, the Sonso community experience high levels of infanticide (Lowe et al. 2019, 2020).

192 A medium altitude rainforest ( 1100m) with significant annual rainfall ( $1500 \mathrm{~mm}$ per year)

193 the area is slightly more seasonal than true rainforest with a distinct dry-season during

194 December-March and a drier season during June-August (Newton-Fisher 1999).

196 Ethical note

197 Data collection was observational and adhered to the International Primatological Society's

198 Code of Best Practice for Field Primatology (MacKinnon et al. 2014). All applicable

199 international, national, and institutional guidelines for the care of animals were followed. 
200 Research was conducted under approval by the Uganda Wildlife Authority and the Uganda

201 National Council for Science and Technology. All work was in accordance with the ethical

202 standards of the Budongo Conservation Field Station at which the study was conducted.

\section{Data collection}

205 Researchers and a team of field assistants followed chimpanzees daily (Waibira: from 06:00

206 to 18:00; Sonso: from 07:00 to 16:30). Long-term data collection included continuous focal

207 individual activity and party composition taken on a 15-min scan basis. In addition, all

208 unusual events or otherwise remarkable behaviour were recorded in detail in logbooks for

209 each community, including births, deaths, and associated descriptions of behaviour (Sonso:

210 since 1993; Waibira: since 2011).

212 In addition to long-term records, AS, PF, EF, CF, DT and $\mathrm{CH}$ together with field-assistants

213 SA, JA, GA, BC, and GM of the Budongo Conservation Field Station observed the extended

214 carry events we report. KET and UP are typically comfortable with the presence of human

215 observers; however, following the death of KETs infant we avoided selecting her as a focal

216 individual because we observed apparent signs of greater than typical arousal (e.g. self-

217 scratching and vigilance) in her interactions with other chimpanzees and we did not want our

218 extended presence to further impact these. Observations of her behaviour were taken on an ad

219 libitum basis whenever she joined the party of chimpanzees that included a focal individual,

220 but we made an effort to locate and observe her for a brief period of time each day to obtain

221 regular updates on her and her infant's state of decomposition. During the births and deaths

222 of UP's infants, regular research practices had been adjusted due to the Covid19 pandemic. In

2232020 activities were restricted to shorter hours of observation (7:30 to 13:00) and limited to

$224 \mathrm{CH}$ and the permanent field staff, who focused primarily on health monitoring of the 
225 chimpanzees during this period; in late 2021, at the time of UP's second extended infant

226 carry, restricted research activities had resumed. Researchers and field staff opportunistically

227 noted any unusual behaviour exhibited. Particular attention was given to how the bodies, and

228 in one event a potential substitute object, were transported, the response of nearby individuals

229 to the mother or the carcass, the interactions of the mother with the corpse, and the state of

230 the corpse. We were not able to collect physiological samples from either corpse to perform

231 laboratory analyses on the cause of death, nor we were able to retrieve either body for

232 autopsy.

234 RESULTS

235 Over a combined 40-year period of observations (30 years Sonso, 10 years Waibira) a total of

236191 births were recorded. Of these: 68 (36\%) died in infancy ( $\leq 5$ years) offering

237 opportunities for their mothers to carry the infant's corpse post-mortem. We found no

238 evidence for seasonality as deaths (with a confirmed observation month, $\mathrm{n}=59$ ) occurred

239 throughout the year (Jan n=5; Feb n=2; Mar n=2; April n=3; May n=1; Jun n=3; Jul n=9; Aug

$240 \mathrm{n}=6 ;$ Sep $n=10 ;$ Oct $n=6 ;$ Nov $n=9 ;$ Dec $n=3)$. Of the $n=68$ infant deaths, we excluded $n=3$

241 that died together with their mothers and $n=12$ because they were partially dismembered or

242 cannibalised during infanticides. Of the remaining $n=53$ cases, we were able to estimate the

243 infant's age at death ( \pm 1 month) in $n=46$ cases $(87 \%)$. The majority $(n=25 ; 54 \%)$ died within

244 the first month, $\mathrm{n}=17(37 \%)$ at 1 -month to 1 -year old; $\mathrm{n}=3(7 \%)$ at 1 - to 3 -years old, and $\mathrm{n}=1$

$245(2 \%)$ at 3- to 5-years old.

247 We observed $n=12$ carries of dead infants by their mothers (Table 1), 23\% of observed

248 opportunities $(n=53)$. To be included as a case of dead infant carrying we required that the

249 mother be seen with the infant the day after death was estimated to have occurred. In 9 cases 
250 the minimum carry length observed was 1-3 days, in 3 cases we observed a longer minimum

251 carry of $n=18, n=56$, and $n=89$ days. These are described in more detail below. The 12

252 carries occurred in both primiparous $(\mathrm{n}=1)$ and multi-parous females $(\mathrm{n}=11)$, including a $7^{\text {th }}$

253 born infant. However, these observations are likely an under-estimate of the frequency of

254 dead infant carrying behaviour in Budongo mothers. In $n=36$ the mother reappeared alone

255 and could have carried for an unknown period prior to this. In total there were $\mathrm{n}=29$ cases

256 where the mother and dead infant were seen together, of these $n=12$ included a death with the

257 mother or infanticide with cannibalism. Of the remaining 17 cases, $n=12$ showed carrying of

258 the dead-infant, a rate of $71 \%$. Of the five cases where the mother was observed with the

259 dead infant but did not carry it, all were infanticides.

261 Table 1 Carrying of dead infants by Budongo chimpanzee mothers: mother-infant dyads

262 (with the mother first), mother's age, parity (indicated as multi-parous (multi) or primi-

263 parous (primi)), infant's age, cause of death, duration of carrying

\begin{tabular}{|c|c|c|c|c|c|}
\hline $\begin{array}{l}\text { Mother- } \\
\text { infant }\end{array}$ & $\begin{array}{l}\text { Age mother } \\
\text { (years) }\end{array}$ & Parity & $\begin{array}{l}\text { Age infant } \\
\text { (months) }\end{array}$ & Cause of death & $\begin{array}{l}\text { Minimum } \\
\text { carrying } \\
\text { duration } \\
\text { (days) }\end{array}$ \\
\hline KG-KG2 & $21 \pm 3$ & multi & 0.03 & $\begin{array}{l}\text { still birth } \\
\text { (suspected) }\end{array}$ & 2 \\
\hline ML-ML2 & $26 \pm 3$ & multi & 0.03 & $\begin{array}{l}\text { still birth } \\
\text { (suspected) }\end{array}$ & 1 \\
\hline JN-JN2 & $21 \pm 1$ & multi & 0.5 & unknown & 1 \\
\hline ZM-ZM6 & $41 \pm 5$ & multi & 0.4 & unknown & 1 \\
\hline JN-JN4 & $28 \pm 1$ & multi & 0.25 & infanticide & 3 \\
\hline KU-KU5 & $34 \pm 3$ & multi & 0.1 & $\begin{array}{l}\text { infanticide } \\
\text { (suspected) }\end{array}$ & 2 \\
\hline KL-KL7 & $34 \pm 1$ & multi & 0.12 & infanticide & 2 \\
\hline ML-ML5 & $39 \pm 5$ & multi & 0.06 & $\begin{array}{l}\text { infanticide } \\
\text { (suspected) }\end{array}$ & 3 \\
\hline KET-KYO & $20 \pm 1$ & primi & 25 & $\begin{array}{l}\text { respiratory infection } \\
\text { (inferred) }\end{array}$ & 18 \\
\hline
\end{tabular}




\begin{tabular}{llllll}
\hline KU-KU7 & $40 \pm 3$ & multi & 0.15 & unknown & 2 \\
\hline UP-UP3 & $21 \pm 1$ & multi & 0.25 & unknown & 56 \\
\hline UP-UP4 & $22 \pm 1$ & multi & 0.25 & unknown & 89 \\
\hline
\end{tabular}

\section{Extended dead infant carrying}

266 A detailed description and videos of the observations are available in the Supplementary

267 Materials. Here we provide a summary of the key information.

269 Observation 1: KET, extended dead infant carrying in Waibira

270 KET's first born infant KYO was last seen alive on the $6^{\text {th }}$ of January 2018, aged 25 months.

271 On the 7th of January 2018 KET was observed carrying KYO who appeared lifeless. Other

272 chimpanzees were present and were apparently aware of her arrival with the infant but

273 showed no atypical reactions to KET or the corpse. The likely cause of death was inferred to

274 be respiratory infection. During the first day KET was observed scratching herself repeatedly

275 before approaching a water area and when sitting close to a sub-adult male. These scratches

276 appeared to be a sign of arousal (fast and repeated, and not accompanied by grooming or

277 response waiting). On several occasions she moved her hand over the dead body apparently

278 to chase away the flies. Other than this, during the entire 18-day period, she was never

279 observed to provide any direct maternal care (grooming, inspecting, touching, or peering)

280 other than carrying, and regularly left the body at short distances (up to $5 \mathrm{~m}$ ) without visually

281 monitoring it. She did not stop others from approaching herself or the dead infant. When

282 moving or feeding in a tree, the dead body was usually (15 out of 16 observations) placed in

283 her right leg pocket, when on the ground she carried the body in her hand or arm (see Online

284 Resources). On one occasion a nulliparous young adult female (MON) was observed to

285 briefly carry the corpse in one hand while KET followed her. Across the 18-days KYO's 
286 corpse decomposed, initially increasing in smell. By the $4^{\text {th }}$ day, no hair remained on the

287 body. By the 9th day, the body looked "dried". By the $10^{\text {th }}$ day the pungent smell and number

288 of flies decreased. It is likely that at this stage the body was completely mummified. No other

289 chimpanzees responded noticeably to either the smell or the flies. On the last day of observed

290 carrying, the body was still intact with only eyes missing and one deformed ear.

291

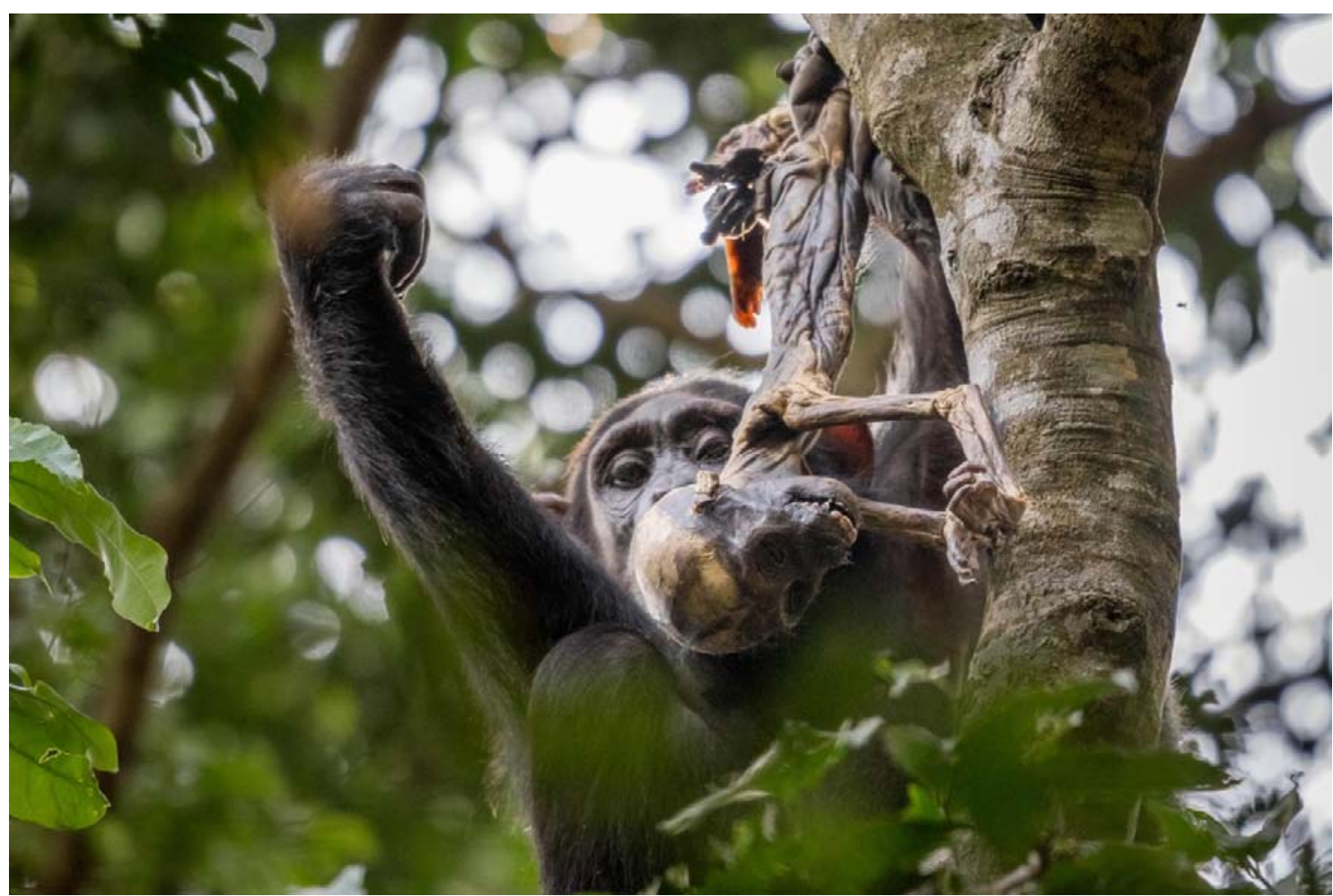

Fig. 1 KET holding KYO's mummified body while sitting on a tree (picture taken by AS on

\section{Observation 2: UP, extended dead infant and substitute object carrying in Sonso}

UP was first seen on the $25^{\text {th }}$ September 2020 with an apparently recently dead infant (UP3), estimated to be 1-week old. Her two previous infants were killed by intra-community infanticide when under 2-weeks old. While some immature individuals ( $<10$ years old) inspected the carcass, no others did, and an adult male showed no interest even while grooming UP. The infant's corpse had started to dry out, but had a noticeable smell and flies, 
301 and was assumed to have died several days earlier. UP was observed on the $4^{\text {th }}$ and $26^{\text {th }}$ of

302 October and the $8^{\text {th }}$ and $19^{\text {th }}$ of November, carrying the corpse on all occasions. She held it in

303 her hand when on the ground and moved it to a leg pocket when climbing or moving in trees.

304 By the $8^{\text {th }}$ November the corpse appeared fully mummified. UP was last seen with the corpse

305 on the $19^{\text {th }}$ November, a minimum carry duration of 56-days (although likely several days

306 longer given corpse appeared partially dry on first observation). She was next seen on the

$30723^{\text {rd }}$ November. When approaching a water hole at the base of a tree, she carried a twig

$308 \sim 50 \mathrm{~cm}$ long in her mouth. As she reached the hole she transferred the twig to her hand and

309 left leg pocket, drank, and then returned it to her mouth (see Online Resources). She

310 continued to carry the twig throughout the morning, including while climbing large trees, and

311 when patrolling with the group over several kilometres. She was seen on the $24^{\text {th }}$ November,

312 and $3^{\text {rd }}$ and $4^{\text {th }}$ December, and was again observed to be carrying a similar twig consistently.

313 She was not seen to put it down on the ground. She was seen briefly on the $5^{\text {th }}$ December, but

314 it was not clear if she had a twig with her, and when she was next observed in the new year

315 (30 ${ }^{\text {th }}$ January) she no longer carried anything.

\section{Observation 3: UP, $2^{\text {nd }}$ extended dead infant carrying in Sonso}

318 UP was first seen on the $28^{\text {th }}$ August 2021 with another dead infant (UP4), estimated to be 1-

319 week old. The infant's corpse had started to dry out but had a strong smell and on the $30^{\text {th }}$ of

320 August flies could be seen hovering around it. Given that the corpse still had a strong smell

321 but was already partially dried, it was assumed to have died at least one week prior. The

322 cause of death was unclear; however, UP was observed with wounds on her head and on her

323 left arm. UP was observed using three main carrying styles when traveling on the ground or

324 moving in trees. She either carried the corpse in one hand (typically left one), in the mouth,

325 or in one leg pocket (typically left one) (see Online Resources). When resting, she placed the 
326 corpse on her lap, in a leg pocket, held it in one hand, or placed it on the ground close to her.

327 UP was not observed providing direct maternal care (e.g. grooming, inspecting, or peering) to

328 the corpse, though she was observed moving her hand around the dead body to chase away

329 flies on several occasions. On one instance UP was victim of aggression from other females

330 during which she dropped the corpse, and then followed the group when traveling and left the

331 corpse behind. Soon after, she was observed returning to retrieve the corpse. We observed a

332 juvenile male orphan $(\mathrm{KJ})$ following her and peering close to the corpse on a few occasions.

333 No other individual was observed taking interest in or showing response to the corpse.

334 Throughout the observation period, UP was often seen in large groups and regularly

335 socialising with adult males (e.g. grooming). On this occasion there were no observations of

336 object carrying. UP was seen carrying the corpse on: the $28^{\text {th }}, 30^{\text {th }}$ and $31^{\text {st }}$ of August; the $2^{\text {nd }}$,

$3376^{\text {th }}, 8^{\text {th }}, 9^{\text {th }}, 11^{\text {th }}, 13^{\text {th }}, 14^{\text {th }}, 16^{\text {th }}, 18^{\text {th }}-23^{\text {rd }}, 24^{\text {th }}, 25^{\text {th }}$ and $29^{\text {th }}$ of September; the $7^{\text {th }}, 12^{\text {th }}, 13^{\text {th }}$,

$33815^{\text {th }}-21^{\text {st }}, 26^{\text {th }}, 28^{\text {th }}$ of October; and the $3^{\text {rd }}, 10^{\text {th }}, 14^{\text {th }}$ and $17^{\text {th }}$ of November. On the $18^{\text {th }}$ of

339 November she was seen without the corpse and had resumed her sexual cycle (with visible

340 sexual swelling) for the first time since the last pregnancy. 


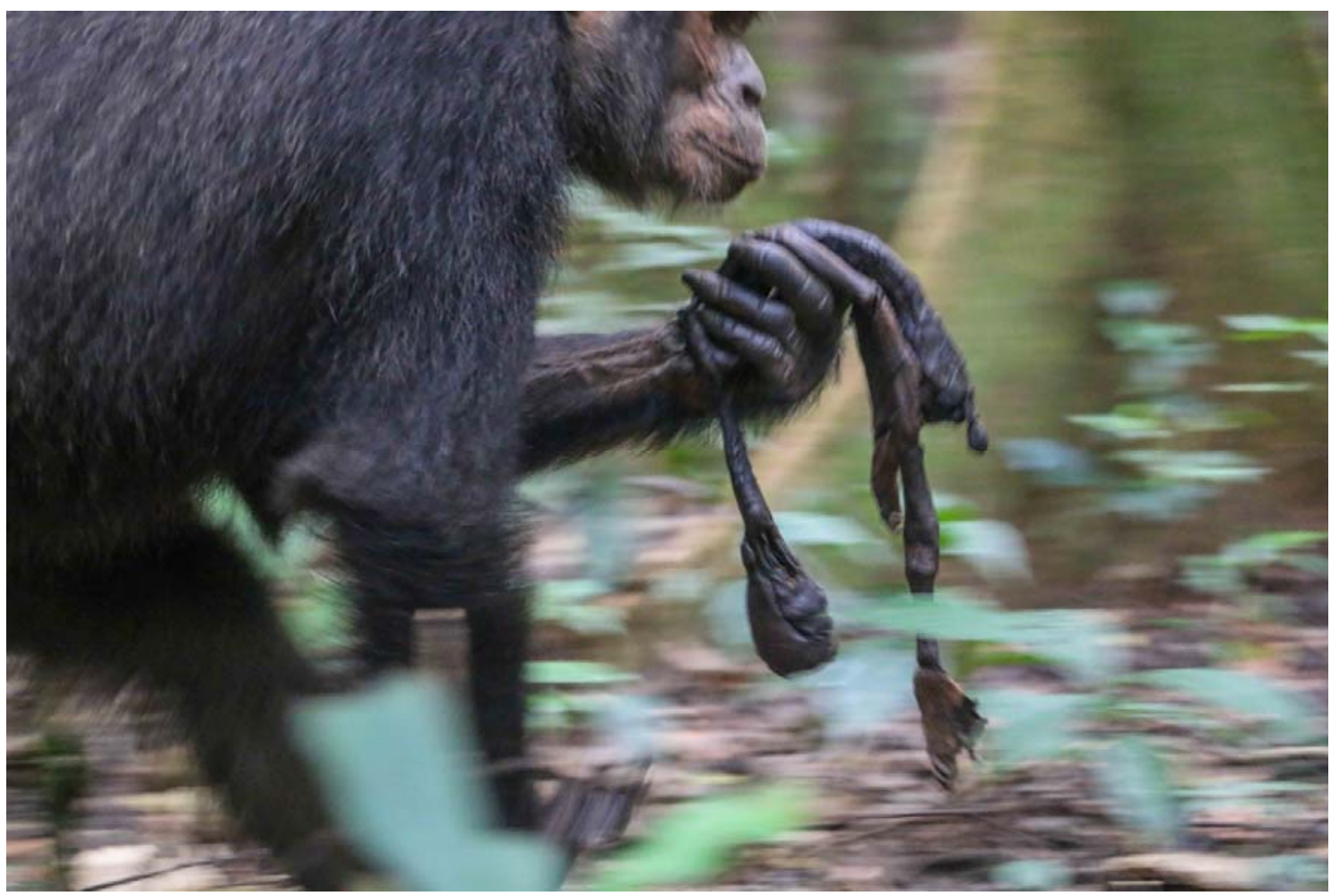

342 Fig. 2 UP carrying UP4's mummified body in her hand while traveling on the ground

343 (picture taken by EF on the 30.08.2021)

\section{DISCUSSION}

346 Human responses to deceased conspecifics are remarkable. Despite the fact that dead

347 individuals have lost all biological importance in terms of kinship, reproduction, or

348 cooperation, humans do not immediately abandon their dead but exhibit a plethora of post-

349 mortem social behaviour towards them, including social gatherings, physical tending, and

350 various burial practices (Parkes et al. 1997). These activities can last for days but are

351 typically terminated by the onset of physical decay, though certain cultures continue to

352 interact with the deceased afterwards (e.g. Hollan 1995). There is archaeological evidence

353 that tending the dead evolved before modern humans (Martinón-Torres et al. 2021), with

354 burials now documented in Homo sapiens neanderthalensis (Rendu et al. 2014) and Homo 
355 naledi (Dirks et al. 2015), and interpreted as an indication of some abstract notion of death

356 and understanding of irreversible loss (Pettitt 2018).

357

358 What do great apes experience, cognitively and emotionally, when losing a socially close

359 individual? In this study we compiled long-term data on chimpanzee mothers that had lost

360 their infants but continued carrying them for days, raising questions about evolutionary

361 continuity in the function of this behaviour and the cognition of understanding death. Dead-

362 infant carrying was practiced by both parous and primiparous mothers with both new-born

363 and older infants. It occurred in at least a fifth, but more likely in almost three quarters of

364 cases (if we consider only those cases in which we were able to observe the mother

365 immediately after the infant's death). As compared to other chimpanzee communities even

366 this value may be an under-estimate of the frequency with which bereaved female

367 chimpanzees carry their infants. The Sonso community, in which we made most of our

368 observations, experiences periodic high levels of infanticide (Lowe et al. 2020). These

369 infanticide cases are often accompanied by some level of cannibalism or dismemberment,

370 and/or the infant is taken from the mother (Lowe et al. 2019), which may limit or shorten

371 mothers' opportunities to carry (Gonçalves and Carvalho 2019; Fernández-Fueyo et al.

372 2021).

373

374 We found no seasonal or infant age effect on dead infant carrying. We also reported three

375 prolonged cases of extended infant carrying. Our observations suggest that these mothers,

376 despite the evidence of irreversible loss including absence of any resemblance to living

377 infants, continued to experience a strong attachment to their deceased infants. Neither female

378 had any other living offspring and one, after eventually abandoning her dead infant after 56

379 days, replaced the corpse with a twig, which she carried for at least another two weeks. In our 
380 cases dead-infant carrying was not accompanied by other forms of maternal care, such as

381 grooming or other forms of maternal attention or interactions, which sometimes occurs very

382 early after an infant's death (Matsuzawa 1997; Biro 2011), suggesting that the two mothers

383 had become aware of the biological facts. Both mothers were forced to use atypical modes of

384 infant carrying, including mouth carrying, more typically used for objects (Lonsdorf et al.

385 2020), as live infants cling to the back or belly of their mothers during travel. Also relevant is

386 that, unlike other groups of animals, chimpanzees do not often cannibalise their own dead

387 infants (but see Fedurek et al. 2020 for two exceptions). Overall, these data suggest that the

388 'unawareness hypothesis' is an unlikely explanation of chimpanzee behaviour towards dead

389 conspecifics.

391 As neither mother appeared to inspect or interact with the infant beyond carrying, our

392 observations do not support the 'learning about death' hypothesis, although maternal social

393 behaviour has been seen in other chimpanzee mothers during the initial stages after death

394 (Matsuzawa 1997; Biro et al. 2010). Similarly, we did not find general support for the

395 'learning to mother hypothesis'. While both KET and UP were inexperienced mothers

396 (primiparous or parous but all offspring killed at under a month old), 10 of the 11 mothers

397 who carried their dead infants were parous and two of these cases were with $6^{\text {th }}$ and $7^{\text {th }}$ born

398 infants. Cases of extended carrying by parous mothers in other groups also suggest limited

399 support the 'learning to mother hypothesis' (Matsuzawa 1997; Biro et al. 2010; Biro 2011;

400 Lonsdorf et al. 2020). However, in line with the fact that younger mothers carry dead infants

401 for longer (Fernández-Fueyo et al. 2021), our observations would fit a suggestion that rare

402 instances of particularly extended carrying across several months might occur when mothers

403 have limited mothering experience. 
405 Because we did not collect any hormonal data to assess the levels of stress associated with

406 dead infant carrying, we were unable to evaluate the 'grief-management hypothesis'.

407 However, the fact that elevated glucocorticoid levels have been reported in chimpanzees and

408 baboons following the death of a socially important group member strongly suggests that

409 these would also be present for chimpanzee mothers in these instances given that the bond

410 they share with their infants is among their most significant, with typically 3-5 years before

411 weaning, and often up to 10-years of daily close contact (Pusey 1983; Lonsdorf and Ross

412 2012; Stanton et al. 2017).

414 Our observations provide more mixed support for other hypotheses. One observation took

415 place during the peak of the driest season of the year, whereas the other two took place

416 during the wettest season of the year. Thus, rather than mummification being the result of

417 favourable climactic conditions, it is possible mummification was observed because the

418 extended carrying durations allowed for it. Recent explorations of several large datasets also

419 found no support for the 'climate hypothesis' (Das et al. 2019; Lonsdorf et al. 2020;

420 Fernández-Fueyo et al. 2021). The evidence for the 'post-parturient condition hypothesis' is

421 similarly mixed; of the three extended carries two infants were new-born, while the other was

422 2-years old. The longest carry reported was for a new-born; however, other new-born infants

423 were carried for short periods of just a few days. One of the three extended carries terminated

424 with the resumption of the mother's reproductive cycles. Our data do not provide

425 straightforward support for the 'post parturient hypothesis' - the extended carrying by UP of

426 her two young new-borns would fit this pattern; however, the extended carrying by KET of

427 her 2-year old infant does not. Other observations of non-mothers carrying dead infants

428 suggest that the post parturient hypothesis cannot explain observed extended carrying alone

429 (Watson and Matsuzawa 2018; Masi 2020). However, hormonal data (that could potentially 
430 also show abnormal hormonal production in either of the two females) are needed to

431 investigate this hypothesis effectively. While the same argument may apply to the "maternal-

432 bond strength hypothesis', with KET's case providing support and UP's cases providing

433 counterevidence, it may be worth noting that these were UP's third and fourth infants in a

434 five-year period, the first two having been killed at under a month old in within-community

435 infanticides (one suspected, one confirmed). As a result, it may be difficult to assess the

436 nature of her bond with these infants. Her apparent use of a 'substitute' in her carrying of a

437 twig together with the even more prolonged second carry suggest she had a particularly

438 strong motivation to carry. These observations, combined with the fact that all recorded

439 instances of carrying in our dataset concern infants who died before weaning age, indicate

440 that maternal behaviours, which are not limited to maternal care, likely play an important role

441 in dead infant carrying (Fernández-Fueyo et al. 2021).

443 Table 2 Hypotheses, predictions, and supporting evidence from the present study for dead 444 infant carrying

\begin{tabular}{lll}
\hline Hypothesis & Prediction & Study support \\
\hline Unawareness & Dead infants are treated as alive. & Unlikely \\
\hline Post-parturition & Young infants are carried for longer. & Mixed \\
\hline Learning about death & Mothers inspect and check state of infant. & Unlikely \\
\hline Grief-management & $\begin{array}{l}\text { Stress levels are lower in mothers carrying } \\
\text { dead infants. }\end{array}$ & Not tested \\
\hline Mearning-to-mother & $\begin{array}{l}\text { Primiparous mothers carry dead infants more } \\
\text { often/for longer. }\end{array}$ & Unlikely \\
\hline Maternal-bond strength & $\begin{array}{l}\text { Strongly bonded and intermediate/old infants } \\
\text { are carried for longer. }\end{array}$ & Mixed \\
\hline
\end{tabular}


447 Within the detailed observations of longer carries, there were two examples of particularly

448 rare behaviour: KET allowing MON to carry KYO, and UP's stick carrying. Carrying the

449 infant of others over periods of time longer than one day is an extremely unusual behaviour

450 in primates, though it has been observed on two occasions in Budongo: adult males snatched

451 new born infants and carried them still alive for at least two days (in one case the male

452 continued to carry the infant for a further two days after its death; Notman and Munn 2003;

453 unpublished long-term data) and was suspected in another case where a daughter was

454 observed carrying her mother's new infant for several days without the mother being present

455 (unpublished long-term data). It is possible that KET tolerated MON's behaviour because of

456 a close bond the two shared, another explanation is that her own bond with the infant's body

457 apparently had decreased by the $13^{\text {th }}$ day.

459 We are not aware of any other reports of primate mothers carrying substitute objects

460 following their infant's death and we are cautious about interpreting this observation.

461 Chimpanzees may carry objects, including twigs, for many reasons; however, a number of

462 features suggest that this was related to UP's infant carrying. Prior to the incident, neither UP

463 nor any other adult Budongo chimpanzees had ever been observed to carry non-food objects

464 between locations. They are notoriously non-stick-tool users (Whiten et al. 1999; Gruber et

465 al. 2011), with a substantial literature suggesting that this is both absent, and robust to

466 scaffolding of its acquisition (Gruber et al. 2009; Gruber 2016). Chimpanzees have been

467 reported at several sites to engage in 'doll' play, where substitute objects, including logs and

468 sticks, are carried as if they were a young infant (Matsuzawa 1997; Kahlenberg and

469 Wrangham 2010). This behaviour typically peaks in juveniles and is more frequent in

470 females and while it is observed in some adult females it ceased once they became mothers

471 (Kahlenberg and Wrangham 2010). The description of log doll use in Bossou is of particular 
472 interest here, as it was carried by a juvenile female during the period that her mother was

473 carrying her sick infant sister, who subsequently died and whose body was also then carried

474 (Matsuzawa 1997). UP's behaviour was observed multiple times over several weeks. Unlike

475 the descriptions of other 'dolls' she was not seen to play with or interact with the object,

476 treating it instead in the same way as she had her infant's corpse. Thus, in addition to object-

477 carrying being associated with the absence of infants in nulliparous mothers, it may also be

478 associated with the loss of an infant in bereaved chimpanzee mothers. In humans, the use of

479 transitional objects has been suggested to function as a coping mechanism for grief following

480 a bereavement (Graham et al. 1987; Lister et al. 2008). A similar suggestion has been made

481 for beluga whales where both wild (Smith and Sleno 1986) and captive (Kilborn 1994),

482 individuals have been seen to carry inanimate objects, apparently as 'surrogates'. The captive

483 whale carried a buoy followed the the removal of her dead calf immediately after birth

484 (Kilborn 1994), and in the wild observations included carrying of planks and netting (Smith

485 and Sleno 1986).

487 To sum up, our observations are consistent with previous observations that chimpanzee

488 mothers respond to the death of their infants with carrying behaviour across communities.

489 Furthermore, our observations support the argument that these mothers act as if they are

490 aware of the loss but are continuing to display a strong attachment to the bodies of their

491 infants and may be affected by psychological processes akin to human grieving.

492 Nevertheless, more detailed hormonal data are needed for a test of this potential mechanism.

493 A combination of ecological conditions favouring mummification, and social factors, such as

494 the strong bond shared between mothers and their infants, may explain the three particularly

495 extended carries by Budongo chimpanzees. While we did not observe other indications of

496 maternal care in these cases, we are cautious about interpreting this as a wider absence in 
497 Budongo mothers. Mothers' pattern of behavioural responses to death may be individually

498 specific and nuanced, resulting from a combination of physical, ecological, and psychological

499 factors, and many more observations are needed to generalise at the population or species

500 level. Our interpretations are limited by the small dataset and the large number of competing

501 and non-mutually exclusive hypotheses, and we encourage researchers and long-term field

502 sites to continue to report the rare behaviours observed in different populations, for example

503 by contributing to open-access databases such as 'ThanatoBase'

504 (http://thanatobase.mystrikingly.com), to allow a richer exploration and more robust

505 hypothesis testing of non-human primates' reaction to death.

507 Acknowledgments

508 We are grateful to all field assistants of the Sonso and Waibira communities who provided

509 essential assistance throughout the observation period. We are thankful to the management,

510 staff, and researchers of the Budongo Conservation Field Station for their support and thank

511 the project's founder Vernon Reynolds. We thank the Royal Zoological Society of Scotland

512 for their long-term financial support to the field station. We thank the Uganda Wildlife

513 Authority and the Uganda National Council for Science and Technology for permission to

514 work in Uganda. We also thank André Gonçalves for helpful comments on a previous version

515 of the draft. AS's fieldwork was supported by the European Research Council project grant to

$516 \mathrm{CC}$ (grant agreement number: 679787). $\mathrm{CH}$ is supported by funding from the European

517 Union's 8th Framework Programme, Horizon 2020 (grant agreement number: 802719).

519 REFERENCES

520 Anderson JR (2016) Comparative thanatology. Curr Biol 26:R553-R556.

$521 \quad$ https://doi.org/10.1016/j.cub.2015.11.010 
522 Anderson JR (2018) Chimpanzees and death. Phil Trans R Soc B 373:20170257.

523 https://doi.org/10.1098/rstb.2017.0257

524 Anderson JR (2020) Responses to death and dying: primates and other mammals. Primates 61:1-7. https://doi.org/10.1007/s10329-019-00786-1

526 Anderson JR, Biro D, Pettitt P (2018) Evolutionary thanatology. Phil Trans R Soc B

$527 \quad 373: 20170262$. https://doi.org/10.1098/rstb.2017.0262

528 Bercovitch FB (2020) A comparative perspective on the evolution of mammalian reactions to

529 dead conspecifics. Primates 61:21-28. https://doi.org/10.1007/s10329-019-00722-3

530 Biro D (2011) Chimpanzee Mothers Carry the Mummified Remains of Their Dead Infants:

531 Three Case Reports from Bossou. In: Matsuzawa T, Humle T, Sugiyama Y (eds) The

532 Chimpanzees of Bossou and Nimba. Springer Japan, Tokyo, pp 241-250

533 Biro D, Humle T, Koops K, et al (2010) Chimpanzee mothers at Bossou, Guinea carry the 534 mummified remains of their dead infants. Curr Biol 20:R351-R352.

$535 \quad$ https://doi.org/10.1016/j.cub.2010.02.031

536 Botting J, van de Waal E (2020) Reactions to infant death by wild vervet monkeys

537 (Chlorocebus pygerythrus) in KwaZulu-Natal, South Africa: prolonged carrying, non-

538 mother carrying, and partial maternal cannibalism. Primates 61:751-756.

539 https://doi.org/10.1007/s10329-020-00851-0

540 Carter AJ, Baniel A, Cowlishaw G, Huchard E (2020) Baboon thanatology: responses of

541 filial and non-filial group members to infants' corpses. R Soc open sci 7:192206.

$542 \quad$ https://doi.org/10.1098/rsos.192206

543 Courtenay J, Santow G (1989) Mortality of wild and captive chimpanzees. Folia Primatol $544 \quad 52: 167-177$ 
545 Cronin KA, van Leeuwen EJC, Mulenga IC, Bodamer MD (2011) Behavioral response of a

546 chimpanzee mother toward her dead infant. Am J Primatol 73:415-421.

547 https://doi.org/10.1002/ajp.20927

548 Das S, Erinjery JJ, Desai N, et al (2019) Deceased-infant carrying in nonhuman anthropoids:

$549 \quad$ Insights from systematic analysis and case studies of bonnet macaques (Macaca radiata)

550 and lion-tailed macaques (Macaca silenus). J Comp Psych 133:156-170.

$551 \quad$ https://doi.org/10.1037/com0000140

552 Dirks PH, Berger LR, Roberts EM, et al (2015) Geological and taphonomic context for the

553 new hominin species Homo naledi from the Dinaledi Chamber, South Africa. Elife

$554 \quad 4: \mathrm{e} 09561$

555 Eggeling WJ (1947) Observations on the Ecology of the Budongo Rain Forest, Uganda. J

$556 \quad$ Ecol 34:20-87. https://doi.org/10.2307/2256760

557 Engh AL, Beehner JC, Bergman TJ, et al (2006a) Behavioural and hormonal responses to

558 predation in female chacma baboons (Papio hamadryas ursinus). Proc R Soc B 273:707-

559 712. https://doi.org/10.1098/rspb.2005.3378

560 Engh AL, Beehner JC, Bergman TJ, et al (2006b) Female hierarchy instability, male

561 immigration and infanticide increase glucocorticoid levels in female chacma baboons.

562 Anim Behav 71:1227-1237. https://doi.org/10.1016/j.anbehav.2005.11.009

563 Fashing PJ, Nguyen N, Barry TS, et al (2011) Death among geladas (Theropithecus gelada):

564 a broader perspective on mummified infants and primate thanatology. Am J Primatol

565 73:405-409. https://doi.org/10.1002/ajp.20902

566 Fedurek P, Tkaczynski P, Asiimwe C, et al (2020) Maternal cannibalism in two populations

567 of wild chimpanzees. Primates 61:181-187. https://doi.org/10.1007/s10329-019-00765-6 
568 Fernández-Fueyo E, Sugiyama Y, Matsui T, Carter AJ (2021) Why do some primate mothers

569 carry their infant's corpse? A cross-species comparative study. Proc R Soc B 288:1-10.

$570 \quad$ https://doi.org/10.1098/rspb.2021.0590

571 Figley CR, Bride BE, Mazza N (1997) Death and trauma: The traumatology of grieving.

$572 \quad$ Taylor \& Francis

573 Fowler A, Hohmann G (2010) Cannibalism in wild bonobos (Pan paniscus) at Lui Kotale.

$574 \quad$ Am J Primatol 72:509-514. https://doi.org/10.1002/ajp.20802

575 Georgiev AV, Melvin ZE, Warketin A-S, et al (2019) Two Cases of Dead-Infant Carrying by

576 Female Zanzibar Red Colobus (Piliocolobus kirkii) at Jozani-Chwaka Bay National Park,

$577 \quad$ Zanzibar. Afr Primates 13:57-60

578 Girard-Buttoz C, Tkaczynski PJ, Samuni L, et al (2021) Early maternal loss leads to short-

579 but not long-term effects on diurnal cortisol slopes in wild chimpanzees. Elife 10:e64134.

$580 \quad$ https://doi.org/10.7554/eLife.64134

581 Gonçalves A, Biro D (2018) Comparative thanatology, an integrative approach: exploring

582 sensory/cognitive aspects of death recognition in vertebrates and invertebrates. Phil Trans

583 R Soc B 373:20170263. https://doi.org/10.1098/rstb.2017.0263

584 Gonçalves A, Carvalho S (2019) Death among primates: a critical review of non-human

585 primate interactions towards their dead and dying. Biol Rev 94:1502-1529.

$586 \quad$ https://doi.org/10.1111/brv.12512

587 Graham MA, Thompson SC, Estrada M, Yonekura ML (1987) Factors affecting

588 psychological adjustment to a fetal death. American Journal of Obstetrics and

589 Gynecology 157:254-257. https://doi.org/10.1016/S0002-9378(87)80145-X

590 Gruber T (2016) Great Apes Do Not Learn Novel Tool Use Easily: Conservatism, Functional

591 Fixedness, or Cultural Influence? Int J Primatol 37:296-316.

592 https://doi.org/10.1007/s10764-016-9902-4 
593 Gruber T, Muller MN, Reynolds V, et al (2011) Community-specific evaluation of tool

594 affordances in wild chimpanzees. Sci Rep 1:128. https://doi.org/10.1038/srep00128

595 Gruber T, Muller MN, Strimling P, et al (2009) Wild Chimpanzees Rely on Cultural

596 Knowledge to Solve an Experimental Honey Acquisition Task. Curr Biol 19:1806-1810.

597 https://doi.org/10.1016/j.cub.2009.08.060

598 Hill K, Boesch C, Goodall J, et al (2001) Mortality rates among wild chimpanzees. J Hum

$599 \quad$ Evol 40:437-450. https://doi.org/10.1006/jhev.2001.0469

600 Hollan D (1995) To the Afterworld and Back: Mourning and Dreams of the Dead among the

601 Toraja. Ethos 23:424-436. https://doi.org/10.1525/eth.1995.23.4.02a00030

602 Hosaka K, Matsumoto-Oda A, Huffman MA, Kawanaka K (2000) Reactions to dead bodies

603 of conspecifics by wild chimpanzees in the Mahale Mountains, Tanzania. Primate Res

$604 \quad 16: 1-15$

605 Hrdy SB (1999) Mother Nature: Ruthless Competitive Nurturing and Tender: Maternal

606 Instincts \& the Shaping of the Species

607 Kahlenberg SM, Wrangham RW (2010) Sex differences in chimpanzees' use of sticks as play

608 objects resemble those of children. Curr Biol 20:R1067-R1068.

609 https://doi.org/10.1016/j.cub.2010.11.024

610 Kaplan J (1973) Responses of mother squirrel monkeys to dead infants. Primates 14:89-91.

$611 \quad$ https://doi.org/10.1007/BF01730518

612 Kappeler PM, van Schaik CP, Watts DP (2012) The Values and Challenges of Long-Term

613 Field Studies. In: Kappeler PM, Watts DP (eds) Long-Term Field Studies of Primates.

614 Springer Berlin Heidelberg, Berlin, Heidelberg, pp 3-18

615 Keverne EB (1988) Central mechanisms underlying the neural and neuroendocrine

616 determinants of maternal behaviour. Psychoneuroendocrinology 13:127-141.

617 https://doi.org/10.1016/0306-4530(88)90010-8 
618 Kilborn SS (1994) Object Carrying in a Captive Beluga Whale (delphinapterus Leucas) as

619 Possible Surrogate Behavior. Mar Mamm Sci 10:496-501.

620 https://doi.org/10.1111/j.1748-7692.1994.tb00510.x

621 Kooriyama T (2009) The death of a newborn chimpanzee at Mahale: reactions of its mother

622 and other individuals to the body. Pan Afr News 16:19-21

623 Lannen PK, Wolfe J, Prigerson HG, et al (2008) Unresolved Grief in a National Sample of

624 Bereaved Parents: Impaired Mental and Physical Health 4 to 9 Years Later. JCO

625 26:5870-5876. https://doi.org/10.1200/JCO.2007.14.6738

626 Leroux M, Monday G, Chandia B, et al (2021) First observation of a chimpanzee with

627 albinism in the wild: Social interactions and subsequent infanticide. Am J Primatol.

628 https://doi.org/10.1002/ajp.23305

629 Lister S, Pushkar D, Connolly K (2008) Current bereavement theory: Implications for art

630 therapy practice. Arts Psychother 35:245-250. https://doi.org/10.1016/j.aip.2008.06.006

631 Lonsdorf EV, Ross SR (2012) Socialization and Development of Behavior. In: The Evolution

632 of Primate Societies. University of Chicago Press, pp 245-268

633 Lonsdorf EV, Wilson ML, Boehm E, et al (2020) Why chimpanzees carry dead infants: an

634 empirical assessment of existing hypotheses. R Soc open sci 7:200931.

635 https://doi.org/10.1098/rsos.200931

636 Lowe AE, Hobaiter C, Asiimwe C, et al (2020) Intra-community infanticide in wild, eastern

637 chimpanzees: a 24-year review. Primates 61:69-82. https://doi.org/10.1007/s10329-019-

$638 \quad 00730-3$

639 Lowe AE, Hobaiter C, Newton-Fisher NE (2019) Countering infanticide: Chimpanzee

640 mothers are sensitive to the relative risks posed by males on differing rank trajectories.

$641 \quad$ Am J Phys Anthropol 168:3-9. https://doi.org/10.1002/ajpa.23723 
642 MacKinnon KC, Riley EP, Garber PA, et al (2014) Code of Best Practices for Field

$643 \quad$ Primatology. https://doi.org/10.13140/2.1.2889.1847

644 Martinón-Torres M, d'Errico F, Santos E, et al (2021) Earliest known human burial in Africa.

$645 \quad$ Nature 593:95-100. https://doi.org/10.1038/s41586-021-03457-8

646 Masi S (2020) Reaction to allospecific death and to an unanimated gorilla infant in wild

647 western gorillas: insights into death recognition and prolonged maternal carrying.

$648 \quad$ Primates 61:83-92. https://doi.org/10.1007/s10329-019-00745-w

649 Matsuzawa T (1997) The death of an infant chimpanzee at Bossou, Guinea. Pan Afr News

$650 \quad 4: 4-6$. https://doi.org/10.5134/143350

651 Nakamichi M, Koyama N, Jolly A (1996) Maternal responses to dead and dying infants in

652 wild troops of ring-tailed lemurs at the Berenty Reserve, Madagascar. Int J Primatol

653 17:505-523. https://doi.org/10.1007/BF02735189

654 Newton-Fisher NE (1999) The diet of chimpanzees in the Budongo Forest Reserve, Uganda:

655 Diet of Budongo chimpanzees. Afr J Ecol 37:344-354. https://doi.org/10.1046/j.1365-

$656 \quad 2028.1999 .00186 . x$

657 Nicolson NA (1991) Maternal behavior in human and nonhuman primates. In: Understanding 658 behavior: What primate studies tell us about human behavior. Oxford Univ. Press NY, pp $659 \quad 17-50$

660 Notman H, Munn J (2003) A Case of Infant Carrying by an Adult Male Chimpanzee in the $661 \quad$ Budongo Forest. Pan Afr News 10:7-9

662 Parkes CM, Langani P, Young B, Speck PW (1997) Death and bereavement across cultures. 663 London: Routledge. Palliat Med 11:427-427

664 Pettitt P (2018) Hominin evolutionary thanatology from the mortuary to funerary realm: the 665 palaeoanthropological bridge between chemistry and culture. Phil Trans R Soc B $666373: 20180212$. https://doi.org/10.1098/rstb.2018.0212 
667 Pusey AE (1983) Mother-offspring relationships in chimpanzees after weaning. Anim Behav

$668 \quad 31: 363-377$. https://doi.org/10.1016/S0003-3472(83)80055-4

669 Ramsay MS, Teichroeb JA (2019) Anecdotes in Primatology: Temporal Trends,

670 Anthropocentrism, and Hierarchies of Knowledge. Am Anthropol 121:680-693.

671 https://doi.org/10.1111/aman.13295

672 Reggente MAL, Alves F, Nicolau C, et al (2016) Nurturant behavior toward dead

673 conspecifics in free-ranging mammals: new records for odontocetes and a general

674 review. Journal of Mammalogy 97:1428-1434. https://doi.org/10.1093/jmammal/gyw089

675 Rendu W, Beauval C, Crevecoeur I, et al (2014) Evidence supporting an intentional

676 Neandertal burial at La Chapelle-aux-Saints. Proc Natl Acad Sci USA 111:81-86.

677 https://doi.org/10.1073/pnas.1316780110

678 Reynolds V (2005) The chimpanzees of the Budongo forest: Ecology, behaviour and

679 conservation. OUP Oxford

680 Rutz C, Webster MM (2021) Ethology adopts the STRANGE framework for animal

681 behaviour research, to improve reporting standards. Ethology 127:99-101.

682 https://doi.org/10.1111/eth.13118

683 Samuni L, Mundry R, Terkel J, et al (2014) Socially learned habituation to human observers

684 in wild chimpanzees. Anim Cogn 17:997-1005. https://doi.org/10.1007/s10071-014-

$685 \quad 0731-6$

686 Smith TG, Sleno GA (1986) Do white whales, Delphinapterus leucas, carry surrogates in

687 response to early loss of their young? Can J Zool 64:1581-1582.

$688 \quad$ https://doi.org/10.1139/z86-237

689 Stanton MA, Lonsdorf EV, Pusey AE, Murray CM (2017) Do juveniles help or hinder?

690 Influence of juvenile offspring on maternal behavior and reproductive outcomes in wild 

https://doi.org/10.1016/j.jhevol.2017.07.012

693 Sugiyama Y, Kurita H, Matsui T, et al (2009) Carrying of dead infants by Japanese macaque

694 (Macaca fuscata) mothers. AS 117:113-119. https://doi.org/10.1537/ase.080919

695 Takeshita RSC, Huffman MA, Kinoshita K, Bercovitch FB (2020) Changes in social

696 behavior and fecal glucocorticoids in a Japanese macaque (Macaca fuscata) carrying her

697 dead infant. Primates 61:35-40. https://doi.org/10.1007/s10329-019-00753-w

698 Thompson CL, Hrit R, Melo LCO, et al (2020) Callitrichid responses to dead and dying

699 infants: the effects of paternal bonding and cause of death. Primates 61:707-716.

$700 \quad$ https://doi.org/10.1007/s10329-020-00824-3

701 Tokuyama N, Moore DL, Graham KE, et al (2017) Cases of maternal cannibalism in wild

702 bonobos (Pan paniscus) from two different field sites, Wamba and Kokolopori,

703 Democratic Republic of the Congo. Primates 58:7-12. https://doi.org/10.1007/s10329-

$704 \quad 016-0582-7$

705 Warren Y, Williamson EA (2004) Transport of dead infant mountain gorillas by mothers and

706 unrelated females. Zoo Biol 23:375-378. https://doi.org/10.1002/zoo.20001

707 Watson CFI, Matsuzawa T (2018) Behaviour of nonhuman primate mothers toward their

708 dead infants: uncovering mechanisms. Phil Trans R Soc B 373:20170261.

709 https://doi.org/10.1098/rstb.2017.0261

710 Webster MM, Rutz C (2020) How STRANGE are your study animals? Nature 582:337-340.

711 https://doi.org/10.1038/d41586-020-01751-5

712 Whiten A, Goodall J, McGrew WC, et al (1999) Cultures in chimpanzees. Nature 399:682-

713 685. https://doi.org/10.1038/21415 
bioRxiv preprint doi: https://doi.org/10.1101/2021.12.22.473786; this version posted January 5, 2022. The copyright holder for this preprint (which was not certified by peer review) is the author/funder. All rights reserved. No reuse allowed without permission.

714 Wilson ML, Boesch C, Fruth B, et al (2014) Lethal aggression in Pan is better explained by

715 adaptive strategies than human impacts. Nature 513:414-417.

716 https://doi.org/10.1038/nature13727

717 